\title{
Cultivar and Developmental Differences in S-protein Concentration and Self-incompatibility in the Japanese Pear
}

\author{
Shao-Ling Zhang ${ }^{1}$ and Shin Hiratsuka ${ }^{2}$ \\ Faculty of Bioresources, Mie University, Tsu, Mie 514-8507, Japan \\ Additional index words. Pyrus pyrifolia, S-allele, self-incompatibility
}

\begin{abstract}
Cultivars of the Japanese pear [Pyrus pyrifolia (Burm.) Nakai] have variable degrees of self-incompatibility (SI) and can be classified into at least three groups: strong, intermediate, or weak SI; as shown by the extent of self-pollen tube growth in the style, and the percentage of fruit set following self-pollination. Following self-pollination, the elongation of pollen tubes in the detached styles of 'Kosui' and 'Kikusui' became increasingly suppressed from 4 days before anthesis ( -4 DAA) to 2 days after anthesis ( 2 DAA). Tube growth of 'Kosui' was more suppressed than that of 'Kikusui' during this period. In 'OsaNijisseiki', however, the rate of tube growth did not vary with stage of stylar development, from -8 to 2 DAA. Pollen tubes elongated much better after cross-pollination than after self-pollination at all stages tested, and the extent of the elongation increased as the styles matured. The concentration of total S-protein (sum of two S-proteins per buffer-soluble protein) increased with stylar development, but the rate of increase varied with the cultivar. The rate was significantly greater in the strongly self-incompatible 'Kosui' than in the moderately self-incompatible 'Kikusui', and was slowest in the weakly selfincompatible 'Osa-Nijisseiki' at all developmental stages. During stylar maturation, the concentration of $S_{4}$-protein, which is common in all cultivars, was highest in 'Kosui', followed by 'Kikusui' and 'Osa-Nijisseiki'. Thus, the cultivar differences in SI expression in the Japanese pear are determined about -4 DAA and appear to be regulated, in part, by the concentration of $S$-proteins produced in the style.
\end{abstract}

The Japanese pear has a gametophytic selfincompatibility (SI) system, which is controlled by $S$-alleles in the pollen and pistil. However, its SI is reduced by high temperatures (Hiratsuka and Tomita, 1989) and mentor pollen (Nakagawa, 1975), and is weak during young bud stages (Hiratsuka et al., 1985). Therefore, the expression of SI in pear varies, not only with the physiological state of the plant but also with environmental factors. Meanwhile, cultivar differences in fruit set in the Japanese pear following self-pollination have been reported by many researchers (Asami, 1935). Based on this information, we have recently compared pollen tube growth in the styles and fruit set after self-pollination in many Japanese pear cultivars. We have concluded that cultivar differences in degree of SI exist, and each cultivar can be roughly classified into strong, intermediate, or weak SI groups (Zhang and Hiratsuka, 1999).

Seven SI alleles have been established in Japanese pears by using paterclinal incompatibility phenomena (Terami et al., 1946). Recently, seven proteins associated with each

Received for publication 28 Sept. 1998. Accepted for publication $16 \mathrm{Dec}$. 1999. The cost of publishing this paper was defrayed in part by the payment of page charges. Under postal regulations, this paper therefore must be hereby marked advertisement solely to indicate this fact.

${ }^{1}$ Current address: Department of Horticulture, Nanjing Agricultural University, Nanjing 210095 , China.

${ }^{2}$ To whom reprint requests should be addressed E-mail address: hiratuka@bio.mie-u.ac.jp allele have been identified (Hiratsuka et al., 1995; Ishimizu et al., 1996; Sassa et al., 1992, 1993). The $S_{6}$ - and $S_{7}$-proteins have been only tentatively established because only one cultivar possessing $S_{6}$ - or $S_{7}$-alleles is available.

In some plant species, bud pollination is effective for overcoming SI (Bredemeijer, 1976; Nasrallah, 1974; Nishio and Hinata, 1977; Shivanna et al., 1978), perhaps because of low concentrations of S-protein in the stigma and/or style (Nasrallah, 1974; Nishio and Hinata, 1977). The SI is also partially overcome by bud pollination in Japanese pears (Hiratsuka et al., 1985), as S-protein concentrations are lower during young bud stages (Hiratsuka and Okada, 1995). However, how cultivar differences in degree of SI are expressed during stylar maturation is unclear.

This study, therefore, was undertaken to determine cultivar differences in the SI response during stylar maturation, and whether or not the degree of SI development is correlated with Sprotein concentration in the style.
Plant materials. Adult trees of the Japanese pear were used at the orchard of Mie Univ., Mie, Japan. Based on our previous report (Zhang and Hiratsuka, 1999), 'Kosui' $\left(\mathrm{S}_{4} \mathrm{~S}_{5}\right)$, 'Kikusui' $\left(\mathrm{S}_{2} \mathrm{~S}_{4}\right)$, and 'Osa-Nijisseiki' $\left(\mathrm{S}_{2} \mathrm{~S}_{4}{ }^{\text {SM }}\right)$ were selected as strongly, moderately, and weakly self-incompatible cultivars, respectively. $\mathrm{S}_{4}{ }^{\mathrm{SM}}$ means stylar-part-mutation of $\mathrm{S}_{4}$-gene, and the $\mathrm{S}_{4}{ }^{\mathrm{SM}}$-protein is the same as the $S_{4}$-protein (Nakashima et al., 1996). Flowers were collected at 2-d intervals from 8 $\mathrm{d}$ before anthesis ( -8 DAA) to $2 \mathrm{~d}$ after anthesis (2 DAA), according to the method of Hiratsuka et al. (1985) (Fig. 1). At 0 DAA flowers were sampled just before opening. Flowers pollinated 2 DAA were prepared by emasculating and covering the flowers with waxed paper bags at -1 DAA.

Determination of style length and fresh weight. All five styles were collected from each of five flowers of three cultivars at each developmental stage. The lengths of 10 randomly selected styles of each cultivar were recorded to the nearest millimeter and a mean length was calculated. This procedure was repeated six times, and mean length and SE of six, 10-style replications were calculated.

For determination of fresh weight $(\mathrm{FW})$, 30 styles from six flowers in each bloom stage were collected, weighed, and the mean FW was calculated. This procedure was repeated six times to obtain the mean FW and SE of six, 30 -style replications.

Pollen tube growth in detached styles. Procedures were based on our previous paper (Zhang and Hiratsuka, 1999). Briefly, on each sampling date pistils from the three cultivars were self-pollinated, and the styles were excised with a razor blade at the calyx end immediately after pollination. Pollen used was prepared $1 \mathrm{~d}$ prior to the experiment by dehiscing and drying the anthers in a bottle containing silica gel. As a control, 'Kosui' $\left(\mathrm{S}_{4} \mathrm{~S}_{5}\right)$ styles that had been pollinated with the cross-compatible cultivar Chojuro $\left(\mathrm{S}_{2} \mathrm{~S}_{3}\right)$ were also prepared. They were then carefully placed on an agar medium containing $0.8 \%$ agar, $10 \%$ sucrose, and $0.01 \% \mathrm{H}_{3} \mathrm{BO}_{3}$ in a petri dish $(9 \mathrm{~cm}$ diameter), and cultured at $25{ }^{\circ} \mathrm{C}$ for $48 \mathrm{~h}$ in the dark. After culture, pollen tubes were stained with cotton blue dye. The numbers of pollen tubes that grew through the entire style and emerged from the excised end of the style were counted under a light transmission microscope. At least three, 10-style replications were examined at each bloom 
stage of each cultivar. The mean percentage of styles with protruding pollen tubes, the mean number of pollen tubes per style, and their respective SE, were calculated.

Stylar protein extraction and electrophoresis. Procedures were based on the method of Hiratsuka et al. (1995). Proteins were extracted by homogenizing $0.3 \mathrm{~g}$ of styles, which had been stored in liquid nitrogen, in a chilled glass homogenizer containing 0.05 м Tris-HCl buffer ( $\mathrm{pH} 8.4$ ) with 150 $\mathrm{mm} \mathrm{NaCl}, 10 \mathrm{~mm}$ L-cysteine, $1 \mathrm{~mm}$ L-ascorbic acid, $1 \mathrm{~mm} \mathrm{CaCl}_{2}, 1 \mathrm{~mm} \mathrm{Na}_{2}$-EDTA, and Polyclar-AT $^{\circledast}\left(0.3 \mathrm{~g} \cdot \mathrm{g}^{-1} \mathrm{FW}\right)$. The homogenate was then centrifuged at $20,000 g_{\mathrm{n}}$ for 10 $\mathrm{min}$, and the supernatant was immediately passed through a Sephadex G-25 (Pharmacia, Uppsala, Sweden) gel column to remove phenolic compounds. The eluent was fractionated and an aliquot from each 3-mL fraction was subjected to the protein assay. Protein fractions were collected, saturated with $\left(\mathrm{NH}_{4}\right)_{2} \mathrm{SO}_{4}$, and centrifuged at $20,000 g_{\mathrm{n}}$ for $10 \mathrm{~min}$. The resulting pellets were redissolved in a small amount of Tris- $\mathrm{HCl}$ buffer (pH 8.4), dialyzed against the same buffer overnight, and subjected to electrophoresis. Protein concentrations of the samples were determined according to the method of Bradford (1976). Extractions of stylar proteins were performed three times from the styles at each bloom stage.

A polyacrylamide gel plate containing $\mathrm{pH}$ 3.5-9.5 ampholine (Pharmacia, Uppsala, Sweden) was used for iso-electric focusing. An aliquot of each sample containing $100 \mu \mathrm{g}$ of protein was subjected to electrophoresis at $10^{\circ} \mathrm{C}$ for $90 \mathrm{~min}$. Running conditions were $1200 \mathrm{~V}(30 \mathrm{~mA})$, and $25 \mathrm{~W}$ for a $200 \times 110 \times$ 1-mm gel. After electrophoresis, the gel was stained using Silver Stain Kit (Wako, Osaka, Japan). The S-proteins moved to the cathode end of the gel. Distance from the end in decreasing order was: $\mathrm{S}_{1^{-}}, \mathrm{S}_{4^{-}}, \mathrm{S}_{5^{-}}, \mathrm{S}_{2^{-}}$, and $\mathrm{S}_{3^{-}}$ proteins (Hiratsuka et al., 1995). The $S_{1^{-}}, S_{3^{-}}$, and $\mathrm{S}_{5}$-proteins were major components of the style, and $\mathrm{S}_{4}$-protein occurred in moderate amounts, whereas $S_{2}$-protein was rare. These S-proteins were also confirmed by their $\mathrm{N}$-terminal amino acid sequences (Nakashima et al., 1996). Based on the above information, we identified each S-protein. To quantify the S-proteins, three samples each of 50, 100, and $300 \mathrm{ng}$ of bovine serum albumin (BSA) were run on the each gel as standards.

Quantification of S-protein. Photographs of stained gels were scanned into a computer through an image scanner (Epson, Nagano, Japan). Each S-protein band was quantified by National Institutes of Health (NIH) image software provided by NIFTY-Serve (Tokyo), by comparing pixel counts of S-protein samples with the BSA standard curve. The relation of pixel counts to BSA concentration showed an almost linear curve from 50 to 300 ng on the same gel, but the gradient sometimes changed depending on gels or photographs used. Therefore, we always used the standard curve made on the same gel for quantification.

Data analysis. Data were calculated using
Microsoft Excel 98 (Microsoft Corp., Redmond, Wash.), and the significance of the difference among the means was analyzed least significant difference (LSD), $P \leq 0.05$. A regression equation was also calculated using Microsoft Excel 98 on the relationship between floral stage and pollen tube growth in each cultivar, and the significance of each regression coefficient was analyzed by $t$ test at $P \leq 0.01$ or 0.05 .

\section{Results}

During $10 \mathrm{~d}$, the length of styles increased from 5 to $10 \mathrm{~mm}$ in all three cultivars (Fig. 2A). Mean style length did not differ significantly among cultivars at -8 or -6 DAA, whereas 'Kosui' styles became significantly longer than those of the other two cultivars at later stages ( 0 and 2 DAA). The FW also increased as much as 2.5 times during $10 \mathrm{~d}$. Differences in FW among cultivars were observed prior to -4 DAA, with 'Osa-Nijisseiki' styles being heaviest, followed by 'Kikusui' and 'Kosui' styles (Fig. 2B). However, no significant cultivar differences were found at -4 DAA or thereafter.

When self-pollinated styles were cultured on the agar medium, pollen tube growth varied with cultivar and age of style (Fig. $3 \mathrm{~A}$ and B). On the day of anthesis, the extent of elongation following self-pollination was 'OsaNijisseiki' > 'Kikusui' > 'Kosui', confirming the observation of Zhang and Hiratsuka

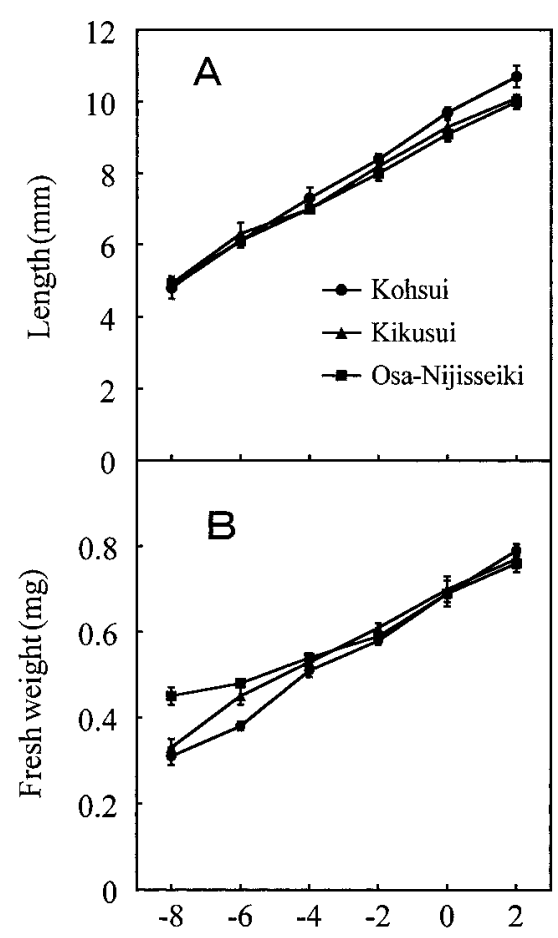

Floral stage (days after anthesis)

Fig. 2. (A) Length and (B) fresh weight of developing styles among three cultivars of Japanese pear differing in degree of self-incompatibility. Vertical bars indicate \pm SE. Each data point represents a mean of six 10-style replications for length, and six 30 -style replications for fresh weight.
(1999). Growth of pollen tubes in selfed styles collected after -6 DAA was repressed more in 'Kosui' and 'Kikusui' than in 'Osa-Nijisseiki'; the repression became stronger in 'Kosui' than in 'Kikusui' as styles matured (Fig. 3A). In contrast, 'Osa-Nijisseiki' pollen tubes grew at a constant rate regardless of stage of flower development. In the styles collected at -6 DAA or before, however, the degree of tube elongation was indistinguishable among the three cultivars. Slightly more pollen tubes protruded from the younger styles except for the 'Kosui' $x$ 'Chojuro' pollination (Fig. 3B). The relationships between the percentage of styles with protruding tubes and DAA indicated regression coefficients of: $-0.951 * *,-0.982 * *,-0.505$, and 0.014 for 'Kosui', 'Kikusui', 'Osa-Nijisseiki', and 'Kosui' x 'Chojuro', respectively. Similarly, coefficients for the number of protruding pollen tubes vs. DAA for the same cultivars were: $-0.913^{*},-0.939^{* *},-0.720$, and 0.597 , respectively with $* *$ or $*$ indicating significance at $P \leq 0.01$ or 0.05 , respectively.

Tube elongation after protrusion was greater in younger than in older styles in 'Kosui' (Fig. 4) and 'Kikusui' (data not shown).

In the cross-compatible pollination, 'Kosui' $\left(\mathrm{S}_{4} \mathrm{~S}_{5}\right) \times$ 'Chojuro' $\left(\mathrm{S}_{2} \mathrm{~S}_{3}\right)$, tube growth increased with the progress of stylar development, until 0 DAA, and the rate of growth was significantly superior to those in self-pollinations at all stages. However, tube elongation was considerably inhibited in styles collected at 2 DAA, perhaps because of stress during bagging and/or emasculation at -1 DAA.

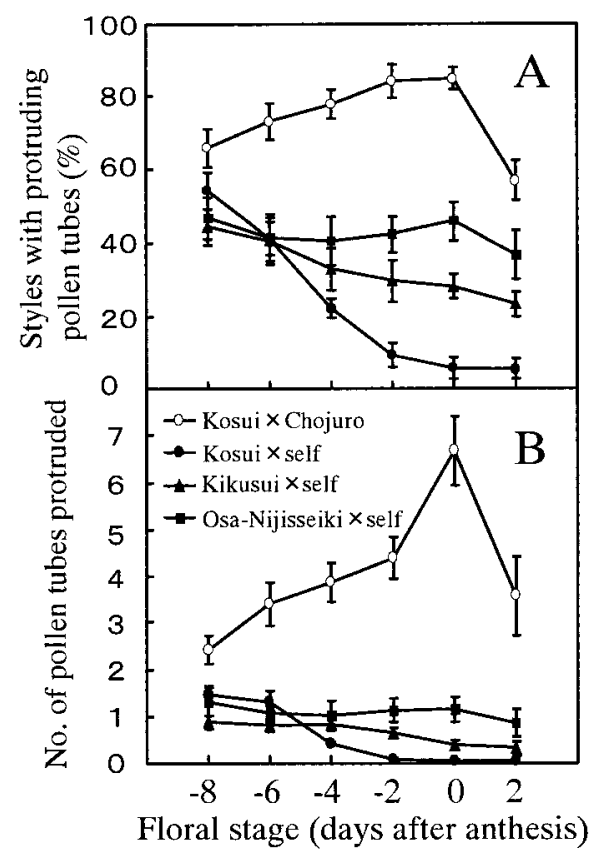

Fig. 3. Comparison of the growth, following selfpollination, of pollen tubes in developing styles among three cultivars of Japanese pear differing in degree of self-incompatibility, and the growth of 'Chojuro' pollen in 'Kosui' styles (compatible). (A) Percentage of styles with protruding pollen tubes. (B) Number of pollen tubes that have grown through style. Vertical bars indicate \pm SE. Each data point represents a mean of three 10 -style replications. 
Electrophoretic patterns of S-proteins (Fig. 5 ) indicated that 'Kosui' contains $\mathrm{S}_{4}$ and $\mathrm{S}_{5}$, 'Kikusui' $\mathrm{S}_{2}$ and $\mathrm{S}_{4}$, and 'Osa-Nijisseiki' $\mathrm{S}_{2}$ and $\mathrm{S}_{4}$ protein bands. The concentration of total S-protein (sum of the two S-proteins) in styles was greatest in 'Kosui', followed by 'Kikusui', and lowest in 'Osa-Nijisseiki' for all the developmental stages tested (Fig. 6). The concentrations of 'Kosui' S-proteins increased rapidly from -8 to -4 DAA, then more gradually thereafter, whereas the concentration increased gradually from -8 to -4 DAA in 'Kikusui' and 'Osa-Nijisseiki', with a relatively more rapid increase thereafter. Thus, we can clearly explain the relationship between cultivar differences in SI development (Fig. 3) and total amount of S-protein in styles older than-4 DAA, but the relationship is obscure in styles younger than -6 DAA; i.e., 'Kosui' pollen tubes grew much better than those of the other two cultivars in spite of a higher concentration of the S-proteins.

Changes in each S-protein concentration also differed considerably among the three cultivars (Fig. 7). The concentration of $\mathrm{S}_{4}$ protein, which is common to all cultivars, increased in a pattern similar to that of total
S-protein, except during the period -2 to 2 DAA; concentrations of $S_{4}$-protein in 'Kosui' and 'Kikusui' during this period were indistinguishable. However, the fluctuations of $\mathrm{S}_{2}$ protein concentration were similar in 'Kikusui' and 'Osa-Nijisseiki', but the former always contained more than the latter, though the differences were not statistically significant from -8 to -2 . Thus, we also could observe positive relationships between increase in concentration of each S-protein and the degree of SI expression in the cultivar.

\section{Discussion}

The SI reaction is usually weak during young bud stages in many plant species, and this was confirmed in Japanese pear. Pollination at -6 and -4 DAA produced inbred seeds (Hiratsuka et al., 1985). In Japanese pears, one explanation advanced to explain why bud pollination overcomes SI is that the immature style is short. Since styles at -4 DAA are about half the length of those at anthesis, pollen tubes can easily grow through the styles (Hiratsuka et al., 1985). Endogenous hormones produced by self-pollination also influence SI

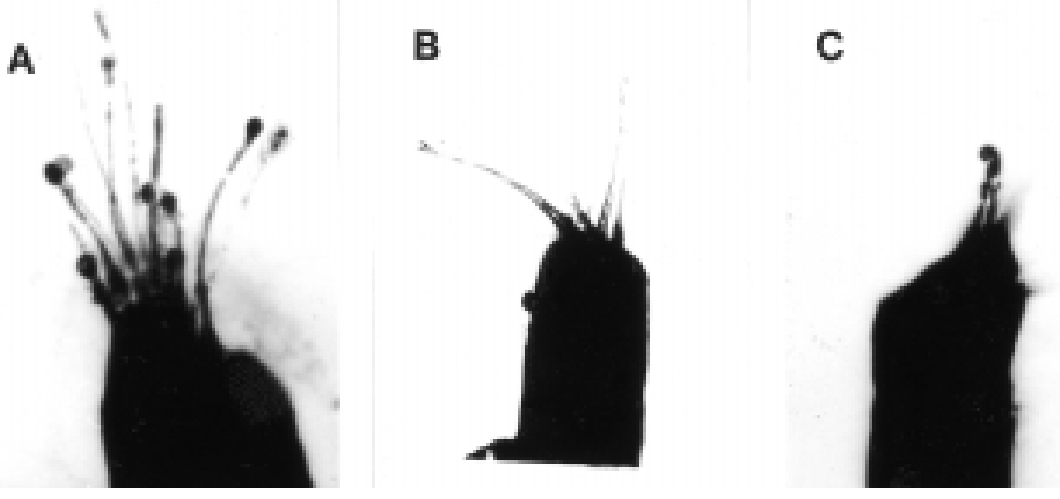

Fig. 4. Growth, following self-pollination, of pollen tubes through the cut end of the style of 'Kosui' pear at various stages of floral development. Floral stage $(\mathrm{DAA}) ;(\mathbf{A})=-8 ;(\mathbf{B})=-6 ;(\mathbf{C})=0$.

expression. The higher levels of gibberellins (GA) and/or auxin induced in the pistil by bud pollination delay senescence of the pistil, allowing it to accept self-pollen to some extent (Hiratsuka et al., 1984). Lastly, the amount of S-protein in the style may not be sufficient to inhibit pollen tube growth at early bud stages (Hiratsuka and Okada, 1995).

Physical characteristics of the style seem to be unrelated to the cultivar differences in SI expression. Although the strongly selfincompatible 'Kosui' possessed somewhat longer styles from -4 to 2 DAA than did the other two cultivars, style lengths in the moderately self-incompatible 'Kikusui' and the weakly self-incompatible 'Osa-Nijisseiki' were almost identical. 'Osa-Nijisseiki' had the heaviest styles, followed by 'Kikusui' and 'Kosui' from -6 to -8 DAA, but almost no differences were observed at stages later than -4 DAA. Accordingly, cultivar differences in SI development are attributable to endogenous chemicals.

Pollen tube elongation differed considerably among the three cultivars (Fig. 3); the differences began to be observed at -4 DAA and became greater as styles matured. This result indicates that development of the SI system begins about -4 DAA and proceeds in different ways in respective cultivars thereafter. This idea matches well with the observation that self-pollination at -4 and -6 DAA can produce Japanese pear fruit with seeds (Hiratsuka et al., 1985).

The most attractive candidates for the mechanism responsible for regulating cultivar differences in SI expression are the Sproteins. Between -4 and 2 DAA, the concentrations of total S-protein (Fig. 6) and respective cultivar-specific S-protein (Fig. 7) increase in parallel with the development of SI in the cultivar. Thus, this development seems to be regulated by S-protein expression in the style of each cultivar. This explanation, however, cannot apply to styles younger than -6 DAA. That is, 'Kosui' pollen tubes grew much better than did those of

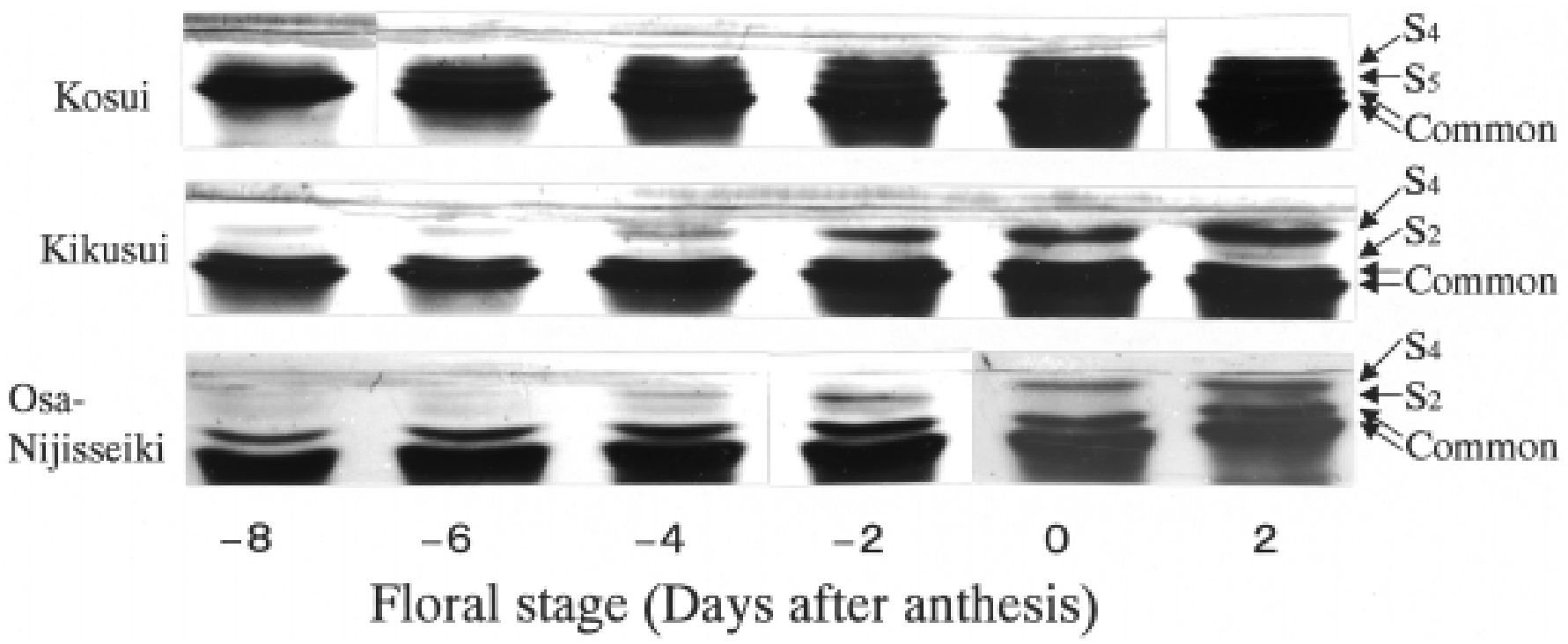

Fig. 5. Silver staining profiles of S-proteins in developing styles of three pear cultivars differing in degree of self-incompatibility. 


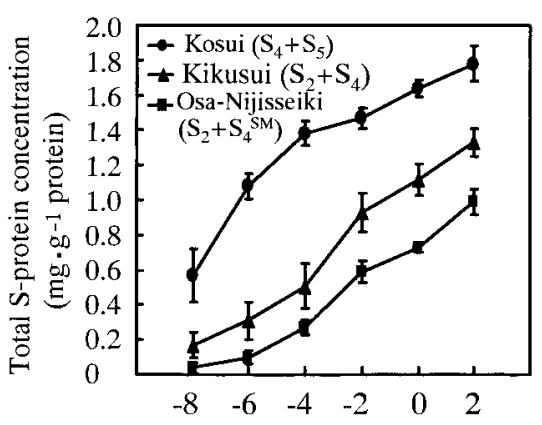

Floral stage (days after anthesis)

Fig. 6. Comparison of total S-protein concentration (sum of the two S-proteins) in developing styles among three pear cultivars differing in degree of self-incompatibility. Vertical bars indicate \pm SE. Each data point represents a mean of three experiments.

the other two cultivars, in spite of the larger amount of the S-protein present during that stage (Figs. 3 and 6). Factors other than Sprotein, such as nutritional supply and development of stylar conducting tissue, should be considered and investigated to explain this phenomenon.

The data presented here suggest that each cultivar of Japanese pear may have a modifier gene(s), which regulates S-gene expression. This idea is partially supported by the recent report from Hawlader and Mian (1997), who found several cultivars with moderately strong SI in radish (Raphanus sativus L.). Meanwhile, Lee et al. (1994) and McCubbin et al. (1997) obtained several transgenic plants of petunia (Petunia $\times$ hybrida Hort. Vilm.Andr.) that were either intermediate in SI expression, and whose styles produced much less S-protein, or were self-compatible, with almost no $\mathrm{S}$-proteins being expressed in the style. Although these plants resulted from tissue culture manipulations, the mechanism is likely to occur naturally among Japanese pear cultivars.

The S-proteins in the Solanaceae are RNases, and their activity seems to be essential for SI response (Huang et al., 1994; Kowyama et al., 1994). Since the S-proteins of Japanese pear also show RNase activity (Hiratsuka et al., 1995; Ishimizu et al., 1996; Sassa et al., 1992), cultivar differences in SI development cannot be explained by S-protein concentration in the style, if the specific activity differs among respective $\mathrm{S}$-proteins or among S-proteins from the styles at different developmental stages. However, judging from the stainability of each S-protein band on the IEF gel by toluidine blue dye, the specific activity seems to differ little among the S-proteins or materials (Hiratsuka et al., 1995).

The information presented here will be useful for pear breeders to produce a cultivar that is self-thinning, because self-compatible cultivars have been bred recently and will be grown commercially in the near future in

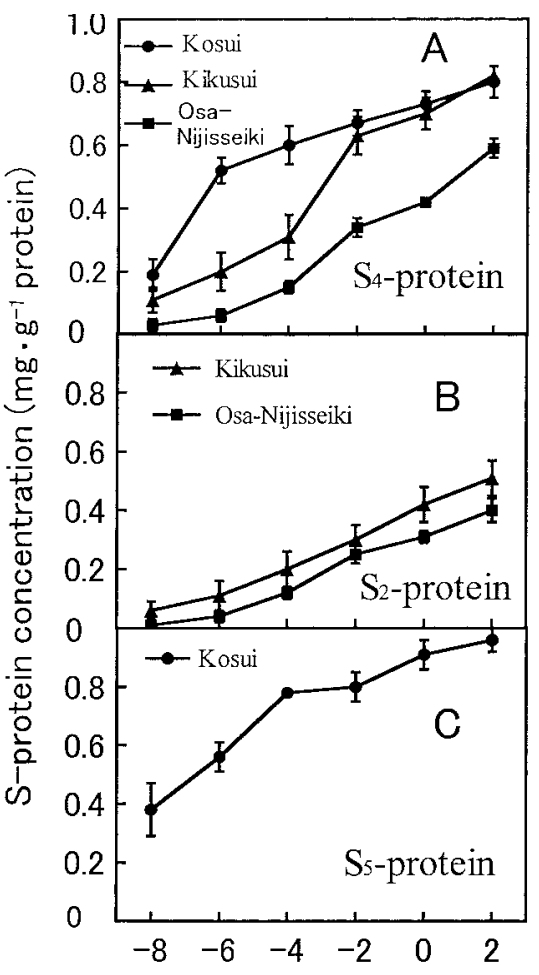

Floral stage (days after anthesis)

Fig. 7. Comparison of respective S-protein concentration in developing styles among three pear cultivars differing in degree of self-incompatibility. Vertical bars indicate \pm SE. Each data point represents a mean of three experiments.

Japan. We are now investigating the specific inhibitory mechanism of S-protein on growth of self-pollen tubes in vitro for a better understanding of cultivar differences in SI expression.

\section{Literature Cited}

Asami, Y. 1935. Explanation on basic problems in pomology (in Japanese). Agr. Hort. 10:229236.

Bradford, M.M. 1976. A rapid and sensitive method for the quantitation of microgram quantities utilizing the principle of protein-dye binding. Anal. Biochem. 72:248-254.

Bredemeijer, G.M.M. 1976. Effect of bud pollination and delayed self-pollination on the induction of a possible rejection peroxidase in styles of Nicotiana alata. Acta Bot. Neerl. 25:107116.

Hawlader, M.S.H. and M.A.K. Mian. 1997. Selfincompatibility studies in local cultivars of radish (Raphanus sativus L.) grown in Bangladesh. Euphytica 96:311-315.

Hiratsuka, S., N. Hirata, T. Tezuka, and Y. Yamamoto. 1985. Self-incompatibility reaction of Japanese pear in various stages of floral development. J. Jpn. Soc. Hort. Sci. 54:9-14.

Hiratsuka, S., M. Hirota, E. Takahashi, and N. Hirata. 1984. The amount of gibberellin-like substances in pistils when overcome self-incompatibility by bud pollination in Japanese pear. Tech. Bul. Fac. Hort. Chiba Univ. 34:1-7.

Hiratsuka, S. and Y. Okada. 1995. Some properties of a stylar protein associated with self-incom- patibility genotype of Japanese pear. Acta Hort. 392:257-264.

Hiratsuka, S., Y. Okada, Y. Kawai, F. Tamura, and K. Tanabe. 1995. Stylar basic proteins corresponding to 5 self-incompatibility alleles of Japanese pears. J. Jpn. Soc. Hort. Sci. 64:471478.

Hiratsuka, S. and A. Tomita. 1989. Incompatible pollen tube growth and protein composition in styles of Japanese pear following high temperature treatments. Euphytica 43:191-196.

Huang, S., H-S. Lee, B. Karunanandaa, and T-H. Kao. 1994. Ribonuclease activity of Petunia inflata $\mathrm{S}$ proteins is essential for rejection of self-pollen. Plant Cell 6:1021-1028.

Ishimizu, T., Y. Sato, T. Saito, Y. Yoshimura, S. Norioka, T. Nakanishi, and F. Sakiyama. 1996. Identification and partial amino acid sequences of seven S-RNases associated with self-incompatibility of Japanese pear, Pyrus pyrifolia Nakai. J. Biochem. 120:326-334.

Kowyama, Y., C. Kunz, I. Lewis, E. Newbigin, A. E. Clarke, and M. A. Anderson. 1994. Selfcompatibility in a Lycopersicon peruvianum variant (LA2157) is associated with lack of style S-RNase activity. Theor. Appl. Genet. 88:859-864.

Lee, H-S., S. Huang, and T-H. Kao. 1994. Sproteins control rejection of incompatible pollen in Petunia inflata. Nature 367:560-563.

McCubbin, A.G., Y-Y. Chung, and T-H. Kao. 1997. A mutant $\mathrm{S}_{3}$ RNase of Petunia inflata lacking RNase activity has an allele-specific dominant negative effect on self-incompatibility interactions. Plant Cell 9:85-95.

Nakagawa, S. 1975. Several problems relating to bearing of fruit trees (in Japanese). Agr. Hort. 50:336-339.

Nakashima, M., K. Kamasaki, H. Kanda, and S. Hiratsuka. 1996. Studies on self-incompatibility in Japanese pears. (XXVI) Comparison of $\mathrm{S}_{4}$-protein expression in styles of 'OsaNijisseiki' and Nijisseiki' (in Japanese). J. Jpn. Soc. Hort. Sci. 65(Suppl.2):150-151.

Nasrallah, M.E. 1974. Genetic control of quantitative variation in self-incompatibility proteins detected by immunodiffusion. Genetics 76:45-50.

Nishio, T. and K. Hinata. 1977. Analysis of Sspecific protein in stigma of Brassica oleracea L. by isoelectric focusing. Heredity 38:391396.

Sassa, H., H. Hirano, and H. Ikehashi. 1992. Selfincompatibility-related RNase in styles of Japanese pear (Pyrus serotina Rehd.). Plant Cell Physiol. 33:811-814.

Sassa, H., H. Hirano, and H. Ikehashi. 1993. Identification and characterization of stylar glycoproteins associated with self-incompatibility genes of Japanese pear, Pyrus serotina Rehd. Mol. Gen. Genet. 241:17-25.

Shivanna, K.R., Y. Heslop-Harrison, and J. HeslopHarrison. 1978. The pollen-stigma interaction; Bud pollination in Cruciferae. Acta Bot. Neerl. 27:107-119.

Terami, H., H. Torikata, and Y. Shimazu. 1946. Analysis of the sterility factors existing in varieties of the Japanese pear (Pyrus serotina REHD. var culta REHD.) (in Japanese with English summary). Studies Hort. Inst. Kyoto Imp. Univ. 3:267-271.

Zhang, S-L. and S. Hiratsuka. 1999. Analysis of varietal differences in self- and crossincompatibility reaction of Japanese pears using stylar culture technique (in Japanese with English summary). J. Jpn. Soc. Hort. Sci. 68:373-383. 